\title{
Measuring Learners' Motivation Level in Massive Open Online Courses
}

\author{
Biyun Huang and Khe Foon Hew
}

\begin{abstract}
Motivation stimulates and sustains learning behavior. It is important to understand learners' motivation, and identify whether the instructional materials can motivate or demotivate students. However, there are relatively few studies that address learners' motivation level in the newly emerged massive open online courses (MOOCs) setting. To shed light in this area, a case study on 27 MOOCs learners' motivation level was conducted. The instructional materials motivation survey (IMMS) instrument has been used to measure learners' motivation. It measures motivation from four dimensions: attention, relevance, confidence, and satisfaction (ARCS). The result showed that most participants' motivation levels were positive, and the participants were satisfied with the instructional materials provided in MOOCs. However, learners also expected improvements in some aspects.
\end{abstract}

Index Terms-ARCS model, IMMS, motivation level, MOOCs.

\section{INTRODUCTION}

Motivation is a crucial drive that stimulates and sustains learning behavior [1]-[4]. Currently, the retention rate of MOOCs is quite low. It is reported that the average Massive open online courses (MOOCs) completion rate is below 7\% [5]. Breslow et al. [6] stated that 154,763 students enrolled for their 6.002x Circuits and Electronics course, but merely around $5 \%$ of them completed the course and earned a certificate. Why did around $90 \%$ students stop learning? Is it because students are not motivated?

It is important to understand students' motivation level in e-learning setting [7]-[11]. By doing so, instructors can then adopt the necessary measures to improve student engagement and learning [10]-[14]. However, there is a lack of empirical research on evaluating learners' motivation level in MOOC settings.

With the aim of filling the knowledge gap in learners' motivation level in MOOC settings, we conducted a survey on learners' motivation level and analyzed learners' motivational needs.

The goal of this research is to evaluate MOOCs learners' motivation level, identify whether different learner groups would have different motivation levels, and propose some suggestions on enhancing motivational features for MOOCs. Research questions are:

1) What are MOOC learners' motivation levels?

2) Is there any difference among different learner groups'

Manuscript received November 28, 2014; revised May 7, 2015.

The authors are with the Division of Information and Technology Studies, Faculty of Education at the University of Hong Kong, Pokfulam Road, Hong Kong (e-mail: lucy99@connect.hku.hk, kfhew@hku.hk). motivation levels?

\section{LITERATURE REVIEW}

TABLE I: LITERATURE ABOUT E-LEARNING AND MOTIVATION

\begin{tabular}{|c|c|c|c|}
\hline Studies & Setting & Participants & Related findings \\
\hline $\begin{array}{l}\text { Chanlin } \\
2009 \text { [7] }\end{array}$ & $\begin{array}{l}\text { A web-based } \\
\text { course "Computer } \\
\text { Ergonomics" }\end{array}$ & $N=40$ & \multirow{4}{*}{$\begin{array}{l}\text { 1. Motivation } \\
\text { influences learning } \\
\text { process in e-learning } \\
\text { context. } \\
\text { 2. motivation level } \\
\text { correlates to } \\
\text { students' learning } \\
\text { achievements. } \\
\text { 3. Motivational } \\
\text { design has positive } \\
\text { influence on course } \\
\text { completion rate in } \\
\text { online learning } \\
\text { context. } \\
\text { 4. ARCS model is } \\
\text { effective in } \\
\text { diagnosing } \\
\text { motivational } \\
\text { problems. } \\
\text { 5. The integral } \\
\text { IMMS instrument of } \\
\text { the ARCS model is } \\
\text { an effective } \\
\text { instrument for } \\
\text { collecting } \\
\text { motivational } \\
\text { information. }\end{array}$} \\
\hline $\begin{array}{l}\text { Johnson, } \\
2012 \text { [15] }\end{array}$ & $\begin{array}{l}2 \text { courses: } \\
\text { English } \\
\text { mathematics } \\
\text { materials; } \\
\text { general } \\
\text { science-themed } \\
\text { EFL reading }\end{array}$ & $N=57$ & \\
\hline $\begin{array}{l}\text { Sha et al., } \\
2012[16]\end{array}$ & $\begin{array}{l}\text { Mobile learning } \\
\text { environment }\end{array}$ & $N=67$ & \\
\hline $\begin{array}{l}\text { Pittengera } \\
\& \text { Doering, } \\
2010[17]\end{array}$ & $\begin{array}{l}4 \text { self-study } \\
\text { pharmacy courses }\end{array}$ & $N=218$ & \\
\hline
\end{tabular}

\section{A. Motivation and e-Learning}

As motivation has complex and influential effects on the learning process, numerous studies have been conducted to find the interrelationship between motivation and learning performance, e.g., [3], [7], [15], [16]. Educators and researchers make substantial efforts to find interventions which can sustain or promote motivation. For example, Chanlin [7]. applied motivational analysis in a web-based course "Computer Ergonomics" and reported that Keller's attention, relevance, confidence, and satisfaction (ARCS) model was an effective model for diagnosing learners' motivational problems and seeking for course improvement. Pittenger \& Doering [17]. found that implementing motivational design in online self-study course could improve course completion rate. Johnson [15]. reported that the Instructional Materials Motivation Survey (IMMS) instrument was an effective instrument for collecting learners' motivational information. Sha et al. [16]. reported the connection between motivation and learning process on self-regulated learning in mobile learning environment. It was 
found that motivation was an important factor that could influence learning process and learning achievements [7]. [16]. In web-based learning contexts, instructors could not observe students' level of engagement and involvement like what they do in a face-to-face learning environment, so implementing investigation on learners' motivation level is a remedy [16] (see Table I). for their findings. Nevertheless, few research studies have been done on evaluating learners' motivation level in the newly emerged MOOCs settings.

\begin{tabular}{|c|c|c|}
\hline Studies & Context & Related findings \\
\hline $\begin{array}{l}\text { Beaven } \text { et al. } \\
2013 \text { [18] }\end{array}$ & $\begin{array}{l}\text { Course: Open Translation } \\
\text { Tools and Practices } \\
N \text { first round }=56 \\
N \text { second round }=35\end{array}$ & \multirow{4}{*}{$\begin{array}{l}\text { 1. Motivation for } \\
\text { enrollment. } \\
\text { Main motivations for } \\
\text { enrollment: } \\
\text { a. for enjoyment or } \\
\text { interest of the topic } \\
\text { b. for knowledge and } \\
\text { skills } \\
\text { c. for interest in open } \\
\text { learning resources } \\
\text { d. for personal } \\
\text { challenge } \\
\text { e. for employment } \\
\text { 2.Factors promoting } \\
\text { student completion } \\
\text { a.recognition; } \\
\text { b. professional } \\
\text { development; } \\
\text { c. forum participation } \\
\text { and interaction } \\
\text { d. supplement to a } \\
\text { credit-bearing course }\end{array}$} \\
\hline $\begin{array}{l}\text { Belanger \& } \\
\text { Thornton, } \\
2013 \text { [19] }\end{array}$ & $\begin{array}{l}\text { Course: Bioelectricity } \\
N=3576\end{array}$ & \\
\hline $\begin{array}{l}\text { DeBoer et al. } \\
2013 \text { [20] }\end{array}$ & $\begin{array}{l}\text { Course: } 6.002 x \text { : Circuits } \\
\text { and Electronics." } \\
N=1173 \text { matrix sample }\end{array}$ & \\
\hline $\begin{array}{l}\text { Breslow et al. } \\
2013 \text { [6] }\end{array}$ & $\begin{array}{l}\text { Course: } 6.002 x \text { : Circuits } \\
\text { and Electronics." } \\
N=1173 \text { matrix sample }\end{array}$ & \\
\hline
\end{tabular}

\section{B. Motivation and MOOCs}

MOOCs are "among the latest e-learning initiative to attain widespread popularity among many universities" [21]. Currently, empirical reports about MOOCs and MOOCs learners' motivation are very limited. Beaven et al. [18] reported that of the 56 total respondents, $73 \%$ expressed that their motivation for enrolling this course was to learn translation skills. In their second round survey, there were 36 respondents. About $46 \%$ of the 36 respondents stated that their expectations were fully met. About $51 \%$ of the 36 respondents expressed their expectations were partly met. Breslow et al. [6] reported the main motivation for students to enroll for the 6.002x Circuits and Electronics was the opportunity to gaining knowledge and skills, i.e. $55.4 \%$ of the 1173 matrix sample. Belanger \& Thornton [19] reported most participants' motivation to enrolling Bioelectricity course was for enjoyment and general interest in the topic. They also discussed factors that promote or inhibit course completion were noting having enough time, not having enough background knowledge, or having difficulty in applying concepts [19]. DeBoer et al. [20]. illustrated students' motivation for course enrollment and the relationship between students' background and their performance. They argued that students' previous educational experience affected students' success. See Table II for the tabulated literature review. These empirical studies have contributed to our understanding of students' motivation for course enrollment and course completion. However, none of the aforementioned studies evaluated learners' motivation level in MOOCs setting, which is a key indicator of students' satisfaction rate on the self-learning materials.

\section{IMMS Survey Instrument}

The IMMS survey instrument is an integral part of ARCS model designed by Keller [4], [9]-[14], [22]. The IMMS instrument is used to measure students' motivation levels. According to Keller [4], four components affect motivation in the learning process: attention, relevance, confidence, and satisfaction (ARCS). All the components contribute to and sustain motivation throughout the learning process [3], [4], [14], [22], [23] To motivate students, four instructional design principles should be met [11].

Principle1. Attention. A variety of tactics should be incorporated to gain and sustain learners' attention.

Principle2. Relevance. Clear goals should be set, and the instruction content should be relevant to learners past experience, academic requirements, or job.

Principle3. Confidence. The instructional environment should help learners build up positive attitude and expectancy towards success.

Principle4. Satisfaction. Help learners attain satisfactory feeling.

Keller states that if the first three principles are met, learners' overall satisfaction will be enhanced accordingly [23], [24]. The IMMS survey was designed to evaluate whether the instructional material is in line with the aforementioned principles and examine what students' motivation levels are.

The IMMS instrument has been applied and proved to have good internal consistency and validity in measuring learners' motivational features in e-learning setting, e.g. [10], [17], [24], [25].

\section{METHODS}

The study adopted a quantitative research method. To gain insights into MOOCs learners' motivation levels, an online survey was administered. The modified IMMS questionnaire was posted on course discussion forums of Coursera and Open2study. The target participants were learners of MOOCs. Within 4 weeks, 27 learners volunteered to participate in this study.

\section{PARTICIPANTS}

This study involved 27 learners who registered on Coursera, Open2study or Khan Academy. The survey was posted on course forums of Coursera and Open2study, but 1 participant commented on Khan Academy's course. 22 participants commented on Coursera courses, and 4 participants commented on Open 2 study courses. There were 22 female and 5 male participants, and their age ranged from 23 to 70 . Among them, 14 students completed all sessions of a course, whereas 13 students did not complete all sessions. Moreover, they received either a bachelor degree or even higher degree. 
See Table III for tabulated information.

TABLE III: DEMOGRAPHICS OF THE SURVEY

\begin{tabular}{|c|c|c|}
\hline Characteristics & Respondents & $\%$ \\
\hline \multicolumn{3}{|l|}{ Gender } \\
\hline Male & 5 & $18.52 \%$ \\
\hline Female & 22 & $81.48 \%$ \\
\hline \multicolumn{3}{|l|}{ Age Group } \\
\hline $23-29$ & 12 & $44.44 \%$ \\
\hline $30-49$ & 6 & $22.22 \%$ \\
\hline $50-70$ & 9 & $33.33 \%$ \\
\hline \multicolumn{3}{|l|}{ Course Platform } \\
\hline Coursera & 22 & $81.48 \%$ \\
\hline Open2study & 4 & $14.81 \%$ \\
\hline Khan Academy & 1 & $3.70 \%$ \\
\hline \multicolumn{3}{|l|}{ Course Completion } \\
\hline Completed & 14 & $51.85 \%$ \\
\hline Uncompleted & 13 & $48.14 \%$ \\
\hline \multicolumn{3}{|l|}{ Education } \\
\hline Bachelor & 7 & $25.93 \%$ \\
\hline Master & 16 & $59.26 \%$ \\
\hline $\mathrm{PhD}$ & 4 & $14.81 \%$ \\
\hline
\end{tabular}

\section{A. Instrument and Data Analyasis}

The IMMS survey consists of 36 items and 4 subscales. The 4 subscales are attention (12 items), relevance (9 items), confidence (9 items), and satisfaction (6 items). It measures learners' motivation level by applying a 5-point symmetrical Likert scale.

There are 10 reverse items (e.g. item 7 of the relevance subscale) in the IMMS instrument. In the reverse item, the lower score the learners give to the reverse items, the higher learners' motivational score is. When using this instrument, the scores of the reverse items should be manually reversed.

To accommodate the massive online courses setting, minor modifications were conducted to the IMMS questionnaire. Some general demographic questions were added, e.g. age, gender, educational background, course name, number of finished sessions. In the second part, the 36 IMMS survey questions were raised. The third part contained one open-ended question for participants to make further comments. The opened-ended question was "Do you have any other comments?"

A scale reliability test was conducted to evaluate the IMMS result. Afterwards, some basic statistics about motivation levels was analyzed. An ANOVA test and an independent t-test was arranged to check whether there was any difference in different learner groups' motivation levels.

\section{RESULTS}

\section{A. Scale Reliability}

The overall reliability of all the scales on standardized Cronbach Alpha was 0.95 ( $n=27$ on 36 items) and the internal consistency for all IMMS scale was 0.75 , which suggested a good reliability of the IMMS result. See Table IV for the tabulated information.

TABLE IV: RELIABILITY OF IMMS RESULT

\begin{tabular}{|c|c|c|c|c|}
\hline Scale & $\begin{array}{c}\text { Cronbach's } \\
\text { Alpha } \\
\end{array}$ & $\begin{array}{c}\text { Cronbach's } \\
\text { Alpha Based on } \\
\text { Standardized } \\
\text { Items }\end{array}$ & $N$ of Items & $N$ \\
\hline Attention & 0.88 & 0.88 & 12 & 27 \\
\hline Relevance & 0.79 & 0.80 & 9 & 27 \\
\hline Confidence & 0.89 & 0.89 & 9 & 27 \\
\hline Satisfaction & 0.86 & 0.86 & 6 & 27 \\
\hline Total scale & 0.95 & 0.95 & 36 & 27 \\
\hline
\end{tabular}

TABLE V: SCORES OF MOTIVATION LEVEL $(N=27)$

\begin{tabular}{c|c|c|c}
\hline Item & Minimum & Maximum & Mean \\
\hline Attention (12 items) & 2 & 4.83 & 3.58 \\
\hline Relevance(9 items) & 2.33 & 4.89 & 3.77 \\
\hline Confidence(9 items) & 1.33 & 4.89 & 3.76 \\
\hline Satisfaction(6 items) & 1.83 & 2.41 & 3.61 \\
\hline Overall(36 items) & 2.58 & 4.63 & 3.69 \\
\hline
\end{tabular}

TABLE VI: RANGE OF MOTIVATION LEVEL

\begin{tabular}{l|c|c|c}
\hline \multicolumn{1}{c|}{ Motivation Level } & Scores & Total $N=27$ & Percentage \\
\hline High Level & $4.00---5.00$ & $N=11$ & $40.74 \%$ \\
\hline Upper Medium Level & $3.50---3.99$ & $N=5$ & $18.52 \%$ \\
\hline Medium Level & $3.00---3.49$ & $N=5$ & $18.52 \%$ \\
\hline Low level & $<3.00$ & $N=6$ & $22.22 \%$ \\
\hline
\end{tabular}

\section{B. Participants' Motivation Level}

Among the 27 participants, the minimum overall motivation level was 2.58, while the maximum overall motivation level was 4.63 . It is noted that the mean overall motivation level score was 3.69 , which was quite positive. About $11(40.74 \%)$ of the 27 respondents had high motivation levels, $5(18.52 \%)$ had upper-medium motivation levels, 5 (18.52\%) had medium level motivation levels, and 5 (22.22\%) had low motivation levels. The research result indicated that the 27 survey participants were mostly satisfied with the course design, with $40.74 \%$ of the respondents had high motivation levels, and $18.52 \%$ had upper-medium motivation levels. There were also differences among participants' motivation levels, as the minimum mean score for overall satisfaction was 2.58 and the maximum mean score was 4.63 . In this research, participant with the highest overall motivation level (score=4.63) and participant with the lowest overall motivation level (score=2.58) were from the same course. See Table V and VI for the tabulated information.

\section{Comparison on Different Learner Groups' Motivation Level}

To identify if there was any difference in the motivation levels among different learner groups, a comparison on different age groups' motivation level was administered. In accordance to their ages, the learners were divided into three 
groups. Group 1, aged from 23-29, $N=12$. Group 2, aged from 30-49, $N=6$. Group 3, aged from 50-70, $N=9$. A nonparametric Kruskal-Wallis test was performed to examine the average motivation level of the three groups, and the result showed that there was no significant differences among the three age groups $(p=0.78)$.

An independent t-test was conducted to compare the motivation levels of the "completed a course" group $(N=14)$ and "not completed a course" group $(N=13)$. The independent t-test result showed that there was significant difference in the average motivation levels for the "completed a course group" $(M=4.01, S D=0.60)$ and "not completed a course group" $(M=$ $3.35, S D=0.59) ; t(25)=2.88, p=0.01$. The result showed that the average motivation level for the "completed a course group" was 0.66 scores higher than the "not completed a course group". This indicated that learners from the "completed a course group" were more motivated than the "not completed a course group".

Moreover, a comparison on learners' motivational scores on each single item of IMMS was conducted. According to the independent t-test results, there were significant differences on the scores of item 4 "This course is so abstract that it was hard to keep my attention on it" of the attention dimension. The scores for question "This course is so abstract that it was hard to keep my attention on it" were "completed a course group" $(M=4.43, S D=0.94)$ and "not completed a course group" $(M=3.16, S D=0.76) ; t(25)=2.79, p=0.01$. The score for "completed a course group" was 1.27 higher than the "not completed a course group". The result suggested that not being able to keep one's attention to the course content could be a reason that hinders learners from completing a course. There were also significant differences on scores of item 8 "I could not really understand quite a bit of the material in this course" of the confidence dimension. The scores for question "I could not really understand quite a bit of the material in this course" were "completed a course group" $(M=4.57, S D=0.76)$ and "not completed a course group" $(M=3.77, S D=1.17) ; t$ $(25)=2.14, p=0.04$. It suggested that both the "completed a course group" and the "not completed a course group" were confident in comprehending the course materials, but the "completed a course group" was relatively more confident in this aspect.

\section{Further Analysis of Motivation Level}

In this session, learners' motivation level was analyzed from four subscales, namely attention, relevance, confidence and satisfaction. As aforementioned, there are some reverse items in each scale. In the reverse items, the lower score the learners give, the higher learners motivational score is. To make the table easy to interpret, we have manually reversed the score. For example, in Q4 of the attention scale "This course is so abstract that it was hard to keep my attention", learners gave a score of 1.19 which meant learners did not think the course was abstract. This indicated learners' real motivation level was high. So we have manually reversed the score to 3.81. The following are the details:

In the attention dimension, the total mean score was 3.58 , the highest score was item $8(M=3.96)$, the lowest scores were item $2 \& 3(M=3.19)$. It suggests that learners' motivation levels were positive in the attention scope. According to the data, learners were most satisfied with the amount of repetition in courses $(M=3.96)$. Learners think that the materials and quality of the writing were acceptable $(M=3.19)$, but there is still room for improvement. See Table VII for tabulated information.

In the relevance dimension, the total mean score was 3.77 , the highest score was item9 $(M=4.26)$, and the lowest score was item $2(M=3.33)$. It showed that learners thought the learning materials were quite relevant to their interest or work. See Table VII for tabulated information.

In the confidence dimension, the total mean score was 3.76, the highest score was item8 $(M=4.19)$, and the lowest score was item $1(M=3.07)$. It indicated that although learners might not be quite confident when they saw the courses for the first time, but afterwards their confidence could grow positively. See Table VII for tabulated information.

In the satisfaction dimension, the total mean score was 3.61, the highest score was item5 $(M=4.15)$, and the lowest score was item $4(M=2.89)$. It indicated that learners were overall satisfied with the courses and their sense of satisfaction would be very high if they could successfully complete the whole course. However, the low score about feedback showed that students were not satisfied with the feedback they could receive. They expected there to be more interaction and feedback from course team. See Table VII for tabulated information.

TABLE VII: MOTIVATION LEVEL FROM 4 DIMENSIONS

\begin{tabular}{|c|c|}
\hline Attention & Mean \\
\hline $\begin{array}{l}\text { Q1 There was something interesting at the beginning of this } \\
\text { course that got my attention. }\end{array}$ & 3.89 \\
\hline Q2 These materials are eye-catching. & 3.19 \\
\hline Q3 The quality of the writing helped to hold my attention. & 3.19 \\
\hline $\begin{array}{l}\text { Q4 This course is so abstract that it was hard to keep my } \\
\text { attention. (Reverse) }\end{array}$ & 3.81 \\
\hline $\begin{array}{l}\text { Q5 The pages of this course look dry and unappealing. } \\
\text { (Reverse) }\end{array}$ & 3.85 \\
\hline $\begin{array}{l}\text { Q6. The way the information is arranged on the pages helped } \\
\text { keep my attention. }\end{array}$ & 3.44 \\
\hline Q7. This course has things that stimulated my curiosity. & 3.70 \\
\hline $\begin{array}{l}\text { Q8. The amount of repetition in this course caused me to get } \\
\text { bored sometimes. (Reverse) }\end{array}$ & 3.96 \\
\hline Q9. I learned some things that were surprising or unexpected. & 3.60 \\
\hline $\begin{array}{l}\text { Q10. The variety of reading passages, exercises, illustrations, } \\
\text { etc., helped keep my attention on the course. }\end{array}$ & 3.26 \\
\hline Q11. The style of writing is boring. (Reverse) & 3.70 \\
\hline $\begin{array}{l}\text { Q12. There are so many words on each page that it is irritating. } \\
\text { (Reverse) }\end{array}$ & 3.89 \\
\hline Relevance & Mean \\
\hline $\begin{array}{l}\text { Q1 It is clear to me how the content of this material is related to } \\
\text { things I already know. }\end{array}$ & 3.70 \\
\hline $\begin{array}{l}\text { Q2There were stories, pictures, or examples that showed me } \\
\text { how this material could be important to some people. }\end{array}$ & 3.33 \\
\hline Q3 Completing this course successfully was important to me. & 3.93 \\
\hline Q4 The content of this material is relevant to my interests. & 4.15 \\
\hline
\end{tabular}




\begin{tabular}{|c|c|}
\hline $\begin{array}{l}\text { Q5 There are explanations or examples of how people use the } \\
\text { knowledge in this course. }\end{array}$ & 3.44 \\
\hline $\begin{array}{l}\text { Q6 The content and style of writing in this course convey the } \\
\text { impression that its content is worth knowing. }\end{array}$ & 3.63 \\
\hline $\begin{array}{l}\text { Q7 This course was not relevant to my needs because I already } \\
\text { knew most of it. (Reverse) }\end{array}$ & 3.41 \\
\hline $\begin{array}{l}\text { Q8 I could relate the content of this course to things I have } \\
\text { seen, done, or thought about in my own life. }\end{array}$ & 4.07 \\
\hline Q9 The content of this course will be useful to me. & 4.26 \\
\hline Confidence & Mean \\
\hline
\end{tabular}

Q1 When I first looked at this course, I had the impression that it would be easy for me.

3.07

\begin{tabular}{l|l} 
Q2 This material was more difficult to understand than I & 3.85 \\
would like for it to be. (Reverse) &
\end{tabular}

\begin{tabular}{l|c}
\hline $\begin{array}{l}\text { Q3 After reading the introductory information, I felt confident } \\
\text { that I knew what I was supposed to learn from this course. }\end{array}$ & 3.56 \\
\hline $\begin{array}{l}\text { Q4 Many of the pages had so much information that it was } \\
\text { hard to pick out and remember the important points. (Reverse) }\end{array}$ & 3.63 \\
\hline $\begin{array}{l}\text { Q5 As I worked on this course, I was confident that I could } \\
\text { learn the content. }\end{array}$ & 4.15 \\
\hline $\begin{array}{l}\text { Q6 The exercises in this course were too difficult. (Reverse) } \\
\text { Q7After working on this course for a while, I was confident } \\
\text { that I would be able to pass a test on it. }\end{array}$ & 4.00 \\
\hline $\begin{array}{l}\text { Q8 I could not really understand quite a bit of the material in } \\
\text { this course. (Reverse) }\end{array}$ & 3.89 \\
\hline $\begin{array}{l}\text { Q9The good organization of the content helped me be } \\
\text { confident that I would learn this material. }\end{array}$ & $\mathbf{4 . 1 9}$ \\
\hline \begin{tabular}{l} 
Satisfaction \\
\hline
\end{tabular}
\end{tabular}

Q1 Completing the exercises in this course gave me a satisfying feeling of accomplishment.

Q2 I enjoyed this course so much that I would like to know more about this topic.

Q3 I really enjoyed studying this course.

Q4 The wording of feedback after the exercises, or of other comments in this course, helped me feel rewarded for my effort.

Q5 I felt good to successfully complete this course.

4.15

Q6 It was a pleasure to work on such a well-designed course.

3.59

\section{CONCLUSION AND DISCUSSION}

According to the responses from the 27 participants, their average motivation level was 3.69. The positive motivation levels indicated that average learners were satisfied with the instructional materials provided on MOOCs. Item 9 of the relevance dimension "the content of this course will be useful to me" achieved the highest mean score 4.26. It indicated that average learners felt the MOOCs were quite relevant to their interest or work. However, it cannot be ignored that item 4 of satisfaction dimension "the wording of feedback after the exercises, or of other comments in this course, helped me feel rewarded for my effort" received the lowest mean score 2.89. It revealed that learners expect more feedback from the course teams. Due to the large number of participants of each course, it might be a huge challenge for the course team to provide sufficient feedback to every individual learner.

Nevertheless, there are several possible ways that could mitigate the heavy workload of giving feedback by the teaching staff. First, instructors may consider having weekly sessions of "ask any questions" where students could post questions for the staff to answer. These questions could be assessed and selected by assistant tutors before sending them to instructors. These "ask any questions" sessions could be video recorded and posted on the course resource page for students to watch. Second, an instructor could randomly select 3-5 student completed exercises, provide informative feedback to them, and post the feedback on the course assignment page. Although providing feedback on 3-5 exercises may not sound significant in relation to the large number of total completed assignments, the feedback would, at least, give an indication to the rest of the students what actually the instructor is looking for, and what the proper answer should be like. Third, an instructor may consider providing his or her own model answers or solutions to the assignments. The instructor may also consider putting an optional lecture video to show how the exercises are worked out. The availability of model answers will provide useful feedback to students.

Regarding to the nonparametric Kruskal-Wallis test result, there was no significant difference among different age groups' motivation levels. Although MOOCs attracted a diversified age groups of learners, it was not evident that people from different age groups would have different motivation levels.

According to the independent t-test result, the "completed course group" was more motivated than the "uncompleted course group". It is consistent with the conjecture that learners with higher motivation level are more likely to complete a course. Moreover, the relatively lower score the "uncompleted course group" gave to the item 4 of the attention dimension suggested that "not being able to keep one's attention" might be a factor that inhibit learners from completing a course. Future study could consider interviewing the "uncompleted course group" learners, investigate their inner motivational needs, and seek for solutions that could help them keep their attention.

This study is a case study on 27 participants' motivation levels. The motivation levels results can only represent the involved participants' perspectives. As the participants were recruited on a voluntary basis, it might also be possible that the volunteer participants were more devoted to MOOCs learning, and thus had relatively higher motivation levels than other MOOCs learners. To expand the generalizability of this research, future studies are needed and a larger scale of investigation covering wider populations could be conducted.

\section{ACKNOWLEDGMENT}

We would like to thank all the participants who volunteered to help out with the survey for their contributions.

\section{REFERENCES}

[1] R. M. Gagné, The Conditions of Learning and Theory of Instruction, New York: Holt, Rinehart and Winston, 1985.

[2] N. Gage and D. Berliner, Educational Psychology, 5th ed., Boston: Houghton Mifflin, 1992.

[3] W. Huang, W. Huang, H. Diefes-Dux, and P. K. Imbrie, "A preliminary validation of attention, relevance, confidence and satisfaction model-based instructional material motivational survey in 
a computer-based tutorial setting," British Journal of Educational Technology, vol. 37, no. 2, pp. 243-259, March 2006.

[4] J. M. Keller, "Development and use of the ARCS model of instructional design," Journal of Instructional Development, vol. 10, no. 3, pp. 2-10, 1987.

[5] K. Jordan, "Initial trends in enrolment and completion of massive open online courses," The International Review of Research in Open and Distance Learning, vol. 15, no. 1, pp. 133-160, February 2014.

[6] L. Breslow, D. E. Pritchard, J. DeBoer, G. S. Stump, A. D. Ho, and D. T Seaton, "Studying learning in the worldwide classroom: Research into edX's first MOOC," Research \& Practice in Assessment, vol. 8, pp. 3-25, 2013.

[7] L. J. ChanLin, "Applying motivational analysis in a web-based course," Innovations in Education and Teaching International, vol. 46 , no. 1, pp. 91-103, 2009.

[8] R. V. Small, "Motivation in instructional design," Teacher Librarian-Seattle, pp. 27-31, June, 2000.

[9] S. H. Song and J. M. Keller, "Effectiveness of motivationally adaptive computer-assisted instruction on the dynamic aspects of motivation," Educational Technology Research and Development, 2001, vol. 49, no. 2, pp. 5-22.

[10] D. A. Cook et al., "Measuring motivational characteristics of courses: Applying Keller's instructional materials motivation survey to a web-based course," Academic Medicine, vol. 84, no. 11, pp. 1505-1509, 2009.

[11] J. Keller and K. Suzuki, "Learner motivation and e-learning design: A multinationally validated process," Journal of Educational Media, vol. 29, no. 3, pp. 229-239, 2004.

[12] J. M. Keller, "Strategies for stimulating the motivation to learn," Performance+ Instruction, vol. 26, no. 8, pp. 1-7. 1987

[13] J. M. Keller, "The systematic process of motivational design," Performance+ Instruction, vol. 26, no. 9-10, pp. 1-8. 1987.

[14] J. M. Keller and T. W. Kopp, "An application of the ARCS model of motivational design," in Instructional Theories in Action. Lessons Illustrating Selected Theories and Models, C. M. Reigeluth, Ed., Hillsdale, NJ: Lawrence Erlbaum Associates, 1987, pp. 289-320.

[15] M. Johnson, "A pilot study examining the motivational effect of instructional materials on EFL learning motivation," Journal of Language and Culture of Hokkaido, pp. 39-47, 2012.

[16] L. Sha et al., "Recognizing and measuring self-regulated learning in a mobile learning environment," Computers in Human Behavior, 2012 , vol. 28 , no. 2, pp. 718-728.

[17] A. Pittenger and A. Doering, "Influence of motivational design on completion rates in online self-study pharmacy-content courses," Distance Education, vol. 31, no. 3, pp. 275-293, 2010.

[18] T. Beaven, A. Comas-Quinn, M. Hauck, B. de los Arcos, and T. Lewis, "The open translation MOOC: Creating online communities to transcend linguistic barriers," OER 13 Creating a Virtuous Circle.
[19] Y. Belanger and J. Thornton. (2013). Bioelectricity: A quantitative approach Duke University's first MOOC. [Online]. Available: http://dukespace.lib.duke.edu/dspace/handle/10161/6216

[20] J. Boer et al. "Diversity in MOOC students' backgrounds and behaviors in relationship to performance in $6.002 \mathrm{x}$," presented at the Sixth Learning International Networks Consortium Conference, 2013.

[21] K. F. Hew and W. S. Cheung, "Students' and instructors' use of massive open online courses (MOOCs): Motivations and challenges," Educational Research Review, vol. 12, pp. 45-58, 2014.

[22] J. M. Keller, "Motivational design of instruction," in Instructional Design Theories and Models: An Overview of Their Current Status, C. M. Reigeluth, Ed., Hillsdale, NJ: Lawrence Erlbaum Associates, 1983, pp. 383-434.

[23] J. M. Keller, Motivational Design for Learning and Performance: The ARCS Model Approach, New York, NY: Springer, 2010

[24] N. Loorbach, O. Peters, J. Karreman, and M. Steehouder, "Validation of the instructional materials motivation survey (IMMS) in a self-directed instructional setting aimed at working with technology," British Journal of Educational Technology, 2014.

[25] W.-H. Huang, "Evaluating learners' motivational and cognitive processing in an online game-based learning environment," Computers in Human Behavior, 2011, vol. 7, no. 2, pp. 694-704.

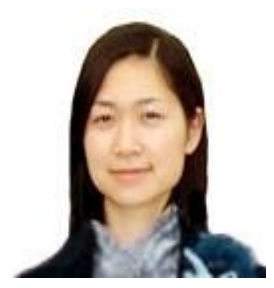

Biyun Huang is a research assistant at the Division of Information and Technology Studies at the Faculty of Education at the University of Hong Kong. She received her M.S. degree at the University of Hong Kong. Her research interests are students' motivation and engagement in e-learning and e-learning design.

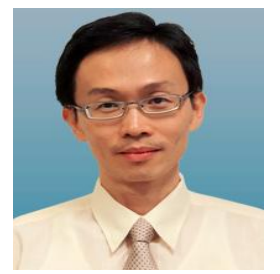

Khe Foon Hew is an associate professor at the Division of Information and Technology Studies at the Faculty of Education at the University of Hong Kong. His research primarily focuses on computer-supported interaction, and technology-mediated learning. He has won several awards including the 2006 Educational Technology Research \& Development Young Scholar Award, the 2011 IGI Global 4th Annual Excellence in Research Journal Award, a Best Paper Award at the 2012 International Conference on ICT in Teaching and Learning, and a Best Presentation Award at the 2013 International Conference on Knowledge and Education Technology. 